\title{
CURQVignettes
}

\section{Interdisciplinary Design Teams for Biomedical Engineering Design}

\section{Conrad Zapanta, Wayne Chung, and Joanna Dickert \\ Carnegie Mellon University, joannad@andrew.cmu.edu}

In the medical device industry, diverse project teams historically create innovative solutions. From corporate medical organizations to engineering and design consulting firms such as GE Healthcare and IDEO, evidence suggests that interdisciplinary teams that work together throughout the entire design process create successful products. However, there are few opportunities for this type of educational experience available to undergraduate students. The Biomedical Engineering (BME) Design course sequence at Carnegie Mellon University introduces BME students from the College of Engineering and product design students from the College of Fine Arts to the development of useful biomedical products in a one-year, research-based experience.

At Carnegie Mellon, BME undergraduates must declare a primary major in one of the other departments in the College of Engineering. Options include chemical engineering, civil and environmental engineering, electrical and computer engineering, materials science and engineering, and mechanical engineering. Grounded in the belief that a biomedical engineer must be deeply trained in both traditional engi- neering practice and biomedical sciences, this requirement benefits from extensive collaborations with sister departments and major medical institutions in Pittsburgh. This collaborative approach, combined with a rigorous engineering education, confers unique depth and breadth to the BME curriculum.

The BME Design course is a graduation requirement for all BME majors at Carnegie Mellon. Although it is not a requirement for product design majors, enrollment reflects significant intellectual diversity as shown in Figure 1. The dynamic composition that shifts each year presents both opportunity and challenge, as course instructors create diverse yet balanced teams with relevant prior experience and skill sets.

In teams ranging in size from four to six, juniors and seniors collaborate to develop a product or device that meets a specific medical need. Teams are selected based on student input, project interest, and the Comprehensive Assessment for Team Member Effectiveness (CATME) system. CATME is a set of tools designed to optimize student experiences in teambased projects. BME Design course instructors use the CATME Team Maker and the CATME Peer Evaluation modules. The CATME Team Maker system ensures team diversity, incorporating considerations such as project preference, class schedule, student primary major, software skills, leadership styles, and big-picture/detail orientation preferences.

\section{Figure 1. \\ 2015-2016 Course Enrollment}

Electrical and Computer Engineering, 7\%

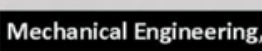
$11 \%$

\section{Civil and Environmental Engineering, $2 \%$}

Biological Sciences, $2 \%$

Product Design, 14\%

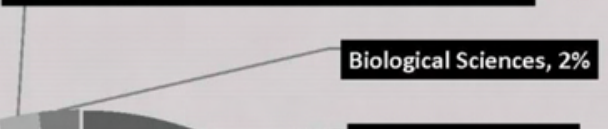

Product Design, $14 \%$

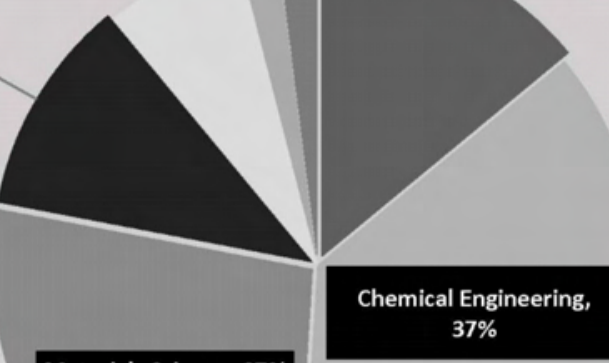

Materials Science, 27\%

In addition to creating a classroom environment in which students collaborate across disciplinary boundaries, the course experience is supported by robust internal and external partnerships. For some project teams, industry partners function as clients, presenting needs to be addressed. Other teams develop their own project ideas. Funding for these projects is provided by the corporate client or by Carnegie Mellon's Undergraduate Research Office (URO). In the fall 2015 semester, URO staff members also began to participate in designated course meetings, providing course-specific guidance relative to proposal writing and project presentations.

During the fall semester of the course, students learn to identify product needs and specify problem definitions. This product ideation is 
followed by completion of an initial prototype and authorship of a written design brief. Opportunities for peer review of this document during class meetings throughout the fall semester prioritize interdisciplinary engagement and build professional communication skills. During the spring semester, the focus shifts to product development, as the teams collaborate to develop a form model and iterative functional prototypes as well as marketing and manufacturing plans for their products. The course experience culminates in team presentations during the university-wide undergraduate research symposium.

CATME peer-evaluation survey results indicate that interdisciplinary teams generally have higher satisfaction than teams composed solely of engineers. The CATME peer-evaluation survey was administered three times over the course of the academic year. In each iteration, students provide self-evaluation scores as well as a score for each of their teammates on the following characteristics:

- Having relevant knowledge and skills $(\mathrm{H})$

- Interacting with teammates (I)

- Contributing to the team's work (C)

- Keeping the team on track $(\mathrm{K})$

Expecting quality (E)

Teams with students from four or five different majors demonstrated higher average scores across each of these categories than teams with representatives from one or two majors.

Direct and indirect assessment measures offer evidence of student learning gains related to written and oral communication competencies with evidence of greater gains since the inception of the formal partnership with the URO. An independent panel of university faculty and staff reviews and scores project funding requests submitted to the URO. All of the proposals were funded for the 2015-2016 course sequence, with five funded in full, in contrast to 33.3 percent that were funded in the previous year. On a scale of 1-5 with 5 as the highest possible score, the average rating for proposals from students in the BME Design course sequence increased from 3.22 for the spring 2015 funding cycle to 3.50 for the spring 2016 funding cycle. Results from the post course iteration of the Classroom Undergraduate Research Experience (CURE) Survey provide student selfassessments of learning in this domain. Respondents $(n=17)$ reported above average gains in their abilities to write a research proposal, present results orally, present results in written papers or reports, present posters, and critique the work of other students. Administered by David Lopatto, professor of psychology at Grinnell College, the CURE survey report includes course-specific results as well as nationally normed data drawn from all participating courses.

In addition, several interdisciplinary teams have won design awards in external competitions such as the BME Start competition sponsored by VentureWell, the MIT Enterprise Forum, and the Social Finance Global Innovation competition sponsored by BNY Mellon. Many teams have also continued commercial development of their design projects after the completion of the course. One such example is the Calibrace+, a flexible brace that alleviates posture issues in patients with Parkinson's disease. Initially developed as the People Prop by a BME design team, it is being marketed commercially by Abilife.

\section{doi: $10.18833 /$ curq/37/4/17}

\section{Research-Intensive Course Designation}

Donna Chamely-Wiik and Bethany Usher

Florida Atlantic University, dchamely@fau.edu; George Mason University, busher@gmu.edu

Integrating undergraduate research into the curriculum is growing in popularity within academic institutions. This practice provides an opportunity for faculty to expose and engage more students to authentic research practices within their courses and scaffold the development of research skills toward a capstone research experience. The process of recognizing research-intensive activities on student transcripts remains limited at many institutions to honors students and through formal theses. A need exists to provide evidence of additional curricular research-intensive activities that do not appear on student transcripts. Such activities could include individual or group classroom projects whereby students are actively engaged in the research process. For students, transcript designation is an opportunity to showcase their research accomplishments. For faculty, this practice can provide credit for intensive undergraduate research mentorship and be applied to annual reports and other promotion portfolios. A few institutions nationwide have begun the process of establishing institutional mechanisms for certifying and designating research-intensive courses. As part of institutional reaccreditation through the Commission on Colleges of the Southern Association of Colleges and Schools (SACSCOC), Florida Atlantic University (FAU) and George Mason University (Mason) implemented quality enhancement plans (QEPs), which included developing university-wide mecha- 